\title{
Nocturnal metiamide treatment in the management of healed duodenal ulceration
}

\author{
M. H. THOMPSON, C. W. VENABLES, P. A. SMITH, AND W. WALKER \\ From the Department of Surgery, Clinical Biochemistry, and Haematology, Royal Victoria Infirmary, \\ Newcastle upon Tyne
}

SUMMARY This paper presents the results of a pilot study to investigate whether the administration of a nocturnal dose of metiamide (the first orally active $\mathrm{H}_{2}$ receptor antagonist) would prevent or delay the relapse of duodenal ulceration after initial ulcer healing. Sixteen patients took part in a double-blind trial to compare metiamide $(400 \mathrm{mg})$ with placebo. Endoscopically confirmed duodenal ulcer relapses occurred in two out of eight on metiamide and six out of eight on placebo. There was a significant prolongation of remission in those on the active drug with an apparent reduction in duodenitis.

The histamine $\mathrm{H}_{2}$-receptor antagonist metiamide inhibits gastric secretion and has been shown to be an effective therapeutic agent in duodenal ulcer disease: its administration over a 28-day period results in ulcer healing in the majority of cases (Lancet, 1975; Thompson et al., 1975). If treatment is stopped after this period a significant number of patients may relapse in the ensuing weeks: only two out of the 14 patients reported previously (Thompson et al., 1975) remained symptom-free in the ensuing year. We, therefore, felt that some kind of maintenance treatment was desirable. Both haematological (Forrest et al., 1975) and mild biochemical (Thompson et al., 1975) side-effects of metiamide have been reported and so continued treatment with doses of the order of $800-1200 \mathrm{mg}$ per day might be associated with a continued risk of such side-effects. Furthermore, a case has been reported where long-term continued administration of metiamide was associated with therapeutic failure because of low plasma concentration of the drug (Blair et al., 1975). If, therefore, a lower dose could be used once the ulcer was healed, it might be possible to maintain ulcer healing while reducing the risk of side effects.

The finding that duodenal ulcer patients secrete more acid overnight than normal (Winkelstein, 1935; James and Pickering, 1949; Levin et al., 1958), and the ability of single oral doses of metiamide grossly to reduce or even abolish this secretion (Milton-Thompson et al., 1974) led us to use a nightly dose only in this trial.

Received for publication 19 November 1976

\section{Methods}

Seventeen ambulant hospital outpatients were entered: 13 had duodenal ulcers and four recurrent ulcers after previous surgery for duodenal ulcers. All patients were treated initially in a double-blind trial of metiamide according to the protocol previously described (Thompson et al., 1975). Those patients whose ulcers failed to heal after administration of placebo were offered 28-days' treatment with metiamide, according to the same basic protocol as the initial trial, endoscopy being repeated on day 28. Thus all patients entering the present trial had endoscopically confirmed healing of their duodenal ulcer. These 17 patients were then re-randomised for the long-term maintenance trial and began this within $\mathbf{4 8}$ hours of their last endoscopic examination.

Nine patients received metiamide in a dose of $400 \mathrm{mg}$ taken at bedtime, and the other eight patients had an apparently identical placebo which they took in the same way. (The tablets were administered on a double-blind basis.) Unmarked, specially prepared, Rennie antacid tablets were issued to each patient for use in case of recurrence of ulcer pain. There were two stomal ulcer patients in each treatment group. The trial was designed to last 12 months, and no other ulcer treatment was given while a patient remained in the trial. No specific dietary advice was given, and no restriction placed on the consumption of tobacco or alcohol.

ASSESSMENT OF PATIENTS

Each patient was seen at weekly intervals, and 
questioned about possible ulcer symptoms. New supplies of the drug were issued, and returned drugs counted. Laboratory tests were undertaken.

\section{RELAPSE OF ULCER DISEASE}

A symptomatic relapse was deemed to have occurred when ulcer pain was present during two consecutive weeks, sufficiently severe to require the taking of antacids.

\section{LABORATORY STUDIES}

A full blood count, platelet count, and differential white blood cell count were made each week. Plasma electrolytes, urea and creatinine, and serum aspartate aminotransferase, lactic dehydrogenase, and alkaline phosphatase were measured each month.

\section{ENDOSCOPIC ASSESSMENT}

A standard method was used throughout the study. After sedation with $30 \mathrm{mg}$ pentazocine intravenously, diazepam was given intravenously, in $2.5 \mathrm{ml}$ aliquots until ptosis or dysarthria occurred. An end-viewing instrument was used initially (Olympus GIF-D). Hyoscine-N-butyl-bromide, $40 \mathrm{mg}$, was given intravenously to facilitate visualisation of the duodenal ulcer when necessary. If a good view was not obtained by this method, a side-viewing instrument was passed (Olympus GF-B2). At all subsequent examinations the same instrument was used by the same investigator.

Endoscopy was performed at three-monthly intervals while remission of disease was maintained, and at any time in the event of a symptomatic relapse occurring. The findings were recorded in a standard manner. The presence or absence of an ulcer or ulcers was noted. In all patients, who had not undergone previous surgery, the amount of endoscopically visualised 'duodenitis' was recorded using the same scoring system (Table 1) employed in the full dose trial.

\section{CALCULATION OF RESULTS}

The numbers of patients who had relapsed or remained in remission was noted for each treatment

Table 1 Scoring systems used to assess duodenitis at endoscopy.

\begin{tabular}{ll}
\hline Duodenitis & Score \\
\hline None & 0 \\
Severity & 1 \\
Slight & 2 \\
Moderate & 3 \\
Severe & 1 \\
Extent & 2 \\
$\quad$ Localised small & 3 \\
$\quad$ More than one area & Throughout cap \\
\hline
\end{tabular}

group each month (one month being four weeks), and comparison made using Fisher's Exact Test.

To investigate whether metiamide induced a more prolonged remission it was necessary to make allowances for the fact that not all the patients had completed the same length of follow-up. This was done by comparing the number of weeks that a patient's ulcer had been in remission with that in relapse-for example, a patient who had been entered into the trial nine months before it ended but whose ulcer had recurred at six months would have 24 weeks in remission and 12 weeks in relapse. The two groups were then compared using a $\chi^{2}$ test.

\section{Results}

Two patients withdrew, fit and well, after six weeks and four months respectively. The first patient has not been included in the results, and the second only up to three months, when endoscopy confirmed a sustained remission. The patients remaining for analysis are shown in Table 2.

Table 2 Patients studied

\begin{tabular}{lll}
\hline & Metiamide & Placebo \\
\hline Mean age (yr) & $47 \cdot 4$ & $47 \cdot 9$ \\
Age range & $31-55$ & $27-68$ \\
Mean length of history (yr) & $10 \cdot 1$ & $12 \cdot 8$ \\
Range & $1-20$ & $3-30$ \\
\hline
\end{tabular}

The differences between the metiamide and placebo groups were not statistically significant ( $P>0.5$ in each case).

After the first two patients had completed the trial, metiamide was withdrawn because of the occurrence of further cases of agranulocytosis in the USA in patients receiving full dosage. As patients had entered the trial at different times, and had reached different stages between 31 and 48 weeks there was a different potential length of time in the trial for each patient, at the time of stopping the trial.

MAINTENANCE OF ULCER HEALING

During the period of the trial, two patients on metiamide relapsed, at eight and 28 weeks, but six out of the eight on placebo had relapsed. This difference just failed to reach significance $(P=0.07)$. In Fig. 1 are illustrated the results in individual patients. In this figure is shown the period that each patient could have remained in the trial had the ulcer not recurred with the time when relapse occurred.

When the length of remission in each group was compared with the period of relapse there was a 


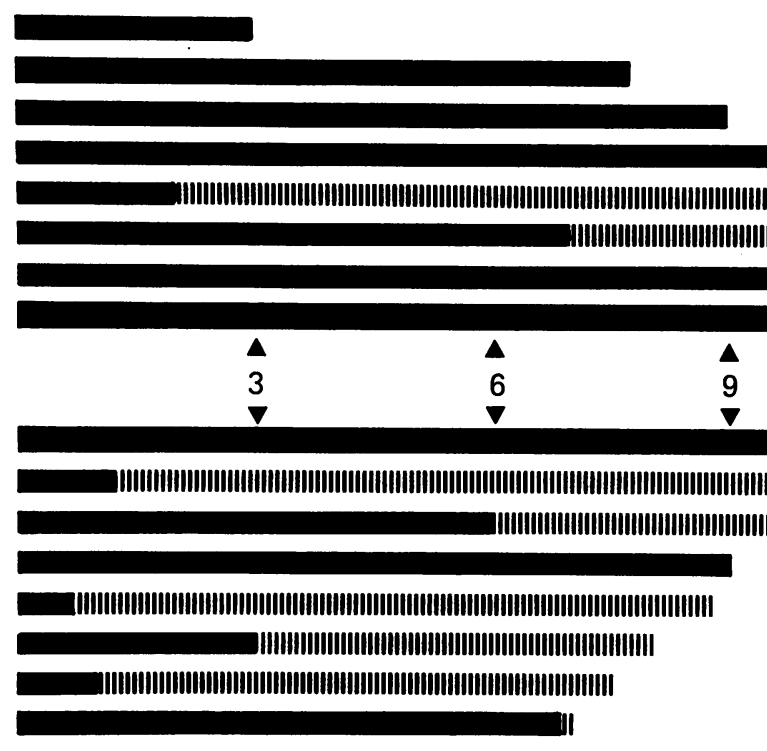

Metiamide

Fig. 1 Ulcer remission in metiamide and placebo treated patients. The length of the bars represents tho length of time the patients could have been in the trial. Time of ulcer relapse represented by start of hatched area.

highly significant prolongation of remission in the patients treated with metiamide (Table 3).

\section{REMISSION OF DUODENITIS}

The amount of duodenitis-that is, the combined score for the extent and severity of the changeobserved at repeated endoscopy is shown in Fig. 2. It can be seen that, in general, once the duodenitis was reduced by 28 days' treatment using a full therapeutic dose, this low-score situation was maintained by nocturnal metiamide treatment. This was not the case in the placebo group where a gradual return to the pretreatment state took place. The scores for severity alone showed a similar pattern.

\section{SYMPTOMS}

All patients were symptom-free at the time of admission to the trial. Some symptoms of oesophageal reflux were noted occasionally during the trial, as was, rarely, mild epigastric pain. In general, though, the patients remained symptom free while in remission. There was no clear difference between metiamide-or placebo-treated patients while in remission. When a symptomatic relapse occurred the

Table 3 Number of patient-weeks of relapse and remission in each group.

\begin{tabular}{|c|c|c|}
\hline & \multicolumn{2}{|c|}{ Total no. of patient weeks } \\
\hline & In remission & In relapse \\
\hline $\begin{array}{l}\text { Metiamide } \\
\text { Placebo }\end{array}$ & $\begin{array}{l}240 \\
156\end{array}$ & $\begin{array}{r}55 \\
128\end{array}$ \\
\hline
\end{tabular}

Placebo

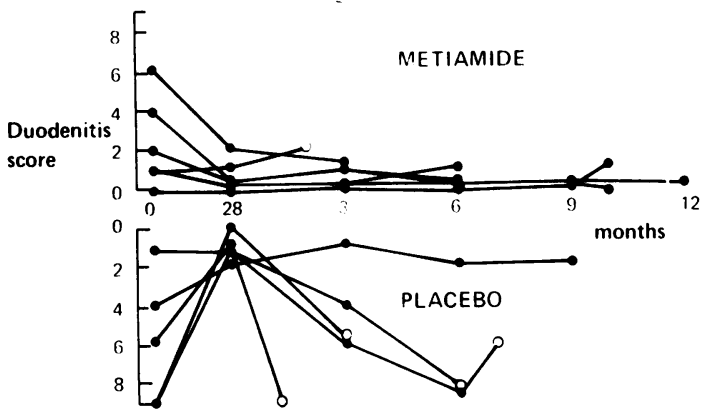

Fig. 2 Remission of duodenitis. 0 : healed ulcer at endoscopy; $\bigcirc$ : endoscopically-confirmed ulcer relapse. The figures 0-28 represent the full-dose treatment period.

pain was readily recognised as ulcer-pain by the patients, and again did not differ with the tablets taken. On one occasion only, a defined symptomatic relapse occurred and no ulcer was seen. The symptom continued, and the ulcer was visualised at endoscopy one month later. On two occasions ulcer relapse was observed in asymptomatic patients, at regular endoscopy. Both patients had been taking placebo. On the remaining 23 occasions that an endoscopic assessment was made, the symptomatic state and endoscopic findings were in agreement.

\section{BIOCHEMICAL AND HAEMATOLOGICAL}

STUDIES

No haematological or biochemical abnormalities of marked degree occurred in any individual patient 
which could be attributed to metiamide. There was, however, a significant rise in the mean serum LDH concentration from 129.7 units/l before any metiamide was given to a peak of 195.7 units at three months $(P=0.002)$ (reference range $50-220$ ), followed by a gradual fall towards, but not reaching, pre-trial values. A similar rise and fall from 120.5 to $149 \cdot 3$ units at four months occurred in the placebo group. This change was not significant $(P=0 \cdot 155)$. There was no accompanying change in serum AST or alkaline phosphatase concentrations.

There was a fall in the mean plasma potassium concentration from $4.3 \mathrm{mmol} / \mathrm{l}$ pre-trial to 3.9 $\mathrm{mmol} / \mathrm{l}$ after one month in the maintenance trial in the metiamide group. This change reverted to normal with continuing treatment.

The mean plasma urea and creatinine concentrations did not change significantly during the trial.

\section{Discussion}

Our earlier study (Thompson et al., 1975) had demonstrated that a single 28 day course of metiamide was associated with healing of ulceration in most patients but it did not seem to induce a prolonged remission. This observation has been confirmed in the present study by the behaviour of our 'placebo' treated patients and also appears to be a problem after treatment with the more recent $\mathrm{H}_{2}$ antagonist cimetidine as recently reported by Haggie et al. 1976. It could be argued that this does not matter as a further course of metiamide could be given when the ulcer relapsed. However, an ulcer relapse can be associated with life threatening complications, such as perforation or haemorrhage, and may be asymptomatic.

This study has shown that nocturnal therapy with metiamide appears to reduce the number of relapses and significantly to increase the length of remission. Before such a therapy could be widely adopted it would need to be shown to be without side-effects. There were no haematological complications in any of our patients but there was a slight rise in serum LDH concentrations. That a similar rise occurred in our placebo-treated patients suggests that a slight laboratory variation accounts for this change. Support for this comes from the fact that there was no associated change in AST concentrations. There were no subjective side-effects and no patient complained of any difficulty in taking the treatment. Returned drug counts suggest that patients took their treatment regularly but this cannot be assured beyond all doubt.
An important feature of this study was the use of repeated endoscopies to assess ulcer healing. This proved to be remarkably acceptable and no patient refused a repeat examination. Although there was a fairly good correlation between symptoms and endoscopic findings, the fact that two ulcers occurred without any symptoms is of considerable importance. This would suggest that repeat endoscopic assessment is required in any study of ulcer relapse.

We thank Mr. B. W. Hawkins of Smith, Kline and French Laboratories for supplies of metiamide and comparable placebo tablets, and Messrs. Nicholas Laboratories for supplies of unmarked Rennies tablets.

\section{References}

Blair, E. L., Grund, E. R., Miller, I. T., Reed, J. D., Sanders D. J., Thompson, M. H., and Venables, C. W. (1975). Metiamide in the Zollinger-Ellison syndrome. American Journal of Digestive Diseases, 20, 1123-1130.

Burland, W. L., Duncan, W. A. M., Hesselbo, T., Mills, J. G., Sharpe, P. C., Haggie, S. J., and Wyllie, J. H. (1975). Pharmacological evaluation of cimetidine, a new histamine $\mathrm{H}_{2}$-receptor antagonist, in healthy man. British Journal of Clinical Pharmacology, 2, 481-486.

Carter, D. C., Forrest, J. A. H., Logan, R., Ansell, I., Lidgard, G., Heading, R. C., and Shearman, D. J. C. (1975). Effect of the histamine $\mathrm{H}_{2}$ receptor antagonist cimetidine on vagally induced gastric secretion in man. I.R.C.S. Journal of Medical Science, 3, 377.

Forrest, J. A. H., Shearman, D. J. C., Spence, R., and Celestin, L. R. (1975). Neutropenia Associated with metiamide. Lancet, 1, 392-393.

Haggie, S. J., Fermont, D. C., and Wyllie, J. H. (1976). Treatment of duodenal ulcer with cimetidine. Lancet, 1 , 983-984.

Henn, R. M., Isenberg, J. I., Maxwell, V., and Sturdevant, R. A. L. (1975). Inhibition of gastric acid secretion by cimetidine in patients with duodenal ulcer. New England Journal of Medicine, 293, 371-375.

James, A. H., and Pickering, G. W. (1949). The role of gastric acidity in the pathogenesis of peptic ulcer. Clinical Science, 8, 181-210.

Levin, E., Kirsner, J. B., Palmer, W. L., and Butler, C. (1948). Nocturnal gastric secretion. Archives of Surgery, 56, 345-356.

Milton-Thompson, C. J., Williams, J. G., Jenkins, D. J. A., and Misiewicz, J. J. (1974). Inhibition of nocturnal acid secretion in duodenal ulcer by one oral dose of metiamide. Lancet, 1, 693-694.

Thompson, M. H., Reed, J. D., Dale, G., and Venables, C. W. (1975). Early clinical experience with metiamide. A histamine $\mathbf{H}_{2}$-receptor antagonist, in patients with duodenal ulcer. American Journal of Digestive Diseases, 20, 1135-1141.

Lancet (1975). Treatment of duodenal ulcer by metiamideA multicentre trial. Lancet, 2, 779-781.

Winkelstein, A. (1935). 169 studies in gastric secretion during the night. American Journal of Digestive Diseases and Nutrition, 1, 778-782. 